\title{
Sampling circulating tumor cells for clinical benefits: how frequent?
}

\author{
Sai Mun Leong ${ }^{1}$, Karen ML Tan ${ }^{1 *}$, Hui Wen Chua ${ }^{1}$, Doreen Tan ${ }^{3}$, Delly Fareda ${ }^{3}$, Saabry Osmany ${ }^{4}$, Mo-Huang Li ${ }^{5}$, \\ Steven Tucker ${ }^{3}$ and Evelyn SC Koay ${ }^{1,2}$
}

\begin{abstract}
Circulating tumor cells (CTCS) are cells shed from tumors or metastatic sites and are a potential biomarker for cancer diagnosis, management, and prognostication. The majority of current studies use single or infrequent CTC sampling points. This strategy assumes that changes in CTC number, as well as phenotypic and molecular characteristics, are gradual with time. In reality, little is known today about the actual kinetics of CTC dissemination and phenotypic and molecular changes in the blood of cancer patients. Herein, we show, using clinical case studies and hypothetical simulation models, how sub-optimal CTC sampling may result in misleading observations with clinical consequences, by missing out on significant CTC spikes that occur in between sampling times. Initial studies using highly frequent CTC sampling are necessary to understand the dynamics of CTC dissemination and phenotypic and molecular changes in the blood of cancer patients. Such an improved understanding will enable an optimal, study-specific sampling frequency to be assigned to individual research studies and clinical trials and better inform practical clinical decisions on cancer management strategies for patient benefits.
\end{abstract}

Keywords: Circulating tumor cells, Therapeutic monitoring, Cancer, Sampling interval, Monitoring frequency

\section{Circulating tumor cells}

Circulating tumor cells (CTCs), shed from primary or metastatic tumor into the blood [1], may represent the source of metastases and hence allow a "liquid biopsy" for molecular characterization to further our understanding of the molecular mechanisms underlying metastasis [2]. In the past decade, advances in technology have allowed the development of assays for CTCs as biomarkers for disease progression and therapeutic response [3]. Numerous studies using different assays have shown that CTCs may be used to predict disease progression and survival in metastatic and possibly even early-stage cancer [4-16]. With the advent of precision medicine, CTCs are currently being pursued as real-time indicators for disease monitoring.

Currently, most studies on CTCs generally employ single or infrequent CTC sampling points [4-16], with the implicit assumption that changes in CTC number, as well as phenotypic and molecular characteristics, are

\footnotetext{
* Correspondence: karen_ml_tan@nuhs.edu.sg

${ }^{1}$ Department of Laboratory Medicine, National University Hospital, Level 3 NUH Main Building, 5 Lower Kent Ridge Road, Singapore 119074, Singapore Full list of author information is available at the end of the article
}

gradual with time. In reality, little is known about the kinetics of these changes in the blood of cancer patients, and the frequencies and time points chosen for their sampling are usually arbitrary and not scientifically validated. Herein, we review examples from literature and our own case studies to show how sub-optimal CTC sampling may result in misleading observations with clinical consequences. The measurement of CTCs is currently not yet recommended in cancer guidelines for diagnosis or to influence treatment decisions [17]. In exploring CTCs as biomarkers of disease progression and therapeutic monitoring, the question of when and how often to sample needs to be answered before CTCs can be used to influence therapeutic decisions.

CTCs were first described in 1869 [1], but the clinical relevance of CTCs was only demonstrated by Cristofanilli et al. in 2004 in metastatic breast cancer patients [4]. In that study, a single measurement of $>5$ CTCs before treatment was shown to be an independent predictor of progression-free survival (PFS) and overall survival (OS) in metastatic breast cancer [4]. More recently, studies in patients with non-metastatic breast cancer also demonstrated that the presence of $\geq 1$ CTC predicted early 
recurrence and decreased OS [5]. The prognostic value of CTCs was also investigated for other cancer types such as prostate, colorectal, lung, and ovarian cancers [6-9], where CTC numbers at a single time point and exceeding a defined cutoff value predicted for increased mortality.

Subsequent studies enumerating CTCs using different assays, at multiple time points before, during, and after treatment in breast, prostate, and colorectal cancers showed that elevated CTC levels measured at any time during the treatment course predicted for disease progression [12-15]. Conversely, reduction in CTCs posttreatment was associated with improved PFS and OS [14-16], suggesting that CTCs represent an indicator of treatment failure and disease progression.

\section{"Saw-toothed" response}

Apart from enhancing prognostication, the use of multiple time points for sampling CTCs may reveal insights into the nature of CTC dissemination in patients' blood. In 2008, using multiple time point measurements, Pachmann et al. described three typical patterns of changes in CTCs observed for non-metastatic breast cancer patients undergoing adjuvant treatment: pattern 1 -decrease in circulating epithelial tumor cells (CETC) count ( $>10$-fold), pattern 2-marginal changes in count ( $<10$-fold), and pattern 3-an increase or initial decrease with subsequent increase ("saw-toothed" pattern) (>10-fold) [18]. Notably, the pattern of change in CETC count during therapy was highly predictive of outcomes, with a highly significant increased relapse-free survival rate for patients with pattern 1 compared to pattern 2, and for patients with pattern 2 compared to pattern 3 [18]. The stratification of patients by their patterns of CTC changes by Pachmann et al. contrasts greatly with most previous studies that used defined cut-off values [4-9] and suggests that the pattern of CTC change itself may be an important predictor for patient outcomes.

Similar saw-toothed patterns were reported in subsequent studies employing different CTC isolation strategies, including the clinically validated FDA-approved CellSearch assay [19-22]. Taken together, these data appear to indicate that saw-toothed-like CTC count patterns may be a common phenomenon occurring in cancer patients undergoing therapy. The mechanism behind this phenomenon is currently unknown, but may be related to differential drug sensitivities of the different intra-tumoral regions that occur as a result of clonal heterogeneity within the primary tumor [23].

The saw-toothed count pattern suggests that CTC dissemination in the blood is not always continuous but may occur in spurts during therapy. It thus follows that depending on the time of CTC measurement, different CTC counts will be obtained and in turn, different conclusions will be drawn with regard to the nature of the patient's real-time therapeutic response. This may explain why some studies, employing very few time points of CTC measurement during therapy, appear not to support a correlation between CTC response and tumor response. For example, Pierga et al. [24] examined the changes in CTC count before and after neoadjuvant therapy for stages II and III breast cancer patients and showed that changes in CTC count did not correlate to complete pathologic response, although CTC detection was proven to be an independent prognostic factor for early relapse [24]. Similar results were reported by Riethdorf et al. [25] for the GeparQuattro trial, which likewise employed a single measurement each for pre- and post-neoadjuvant therapy [25]. In the landmark study by Cristofanilli et al., only $50 \%$ of patients with progressive disease had increased CTC counts [4]. It cannot be ruled out that transient rises in CTC counts occurred in the other $50 \%$ of the patients, but were missed as only a single time point was used in the study. Uncertainty regarding the timing of CTC measurements might thus limit the predictive capacity of single or few time point CTC measurements.

\section{The issue of optimal sampling frequency}

Given that different CTC count patterns may predict for significantly varied relapse-free survival [18], it will be important to distinguish between patients with invariable, gradual, or rapid decline, gradual or rapid increase, or saw-toothed patterns of CTC response. As shown in Fig. 1a, these different patterns cannot be distinguished by infrequent counts. The effect of sub-optimal count frequency on the patient's CTC response pattern is further illustrated by the following case studies:

(i) Using a typical saw-toothed response curve of a breast cancer patient from response group 3, as presented by Pachmann et al. [18], we simulated the count patterns observed when the frequency of blood sampling is halved. Depending on the sampling dates chosen, the patient could have a pattern resembling that of response group 1 (decrease in cell numbers), response group 2 (consistent cell numbers), or response group 3 (increase in cell numbers) when the number of sampling points is decreased from six to three points (Fig. 1b).

(ii) A recent case report of a metastatic breast cancer patient by Marsland and Schuur [19] demonstrated a saw-toothed pattern of CTC counts during the patient's course of therapy (Fig. 2a). CTCs were sampled three-monthly in 2007 and monthly in 2008. Using the CellSearch assay, a spike of CTCs from 0 to 8 was observed in May 2008, which corresponded with disease progression (Fig. 2a). We simulated the count patterns observed when the frequency of blood sampling is halved, using alternate time points. Depending on the 


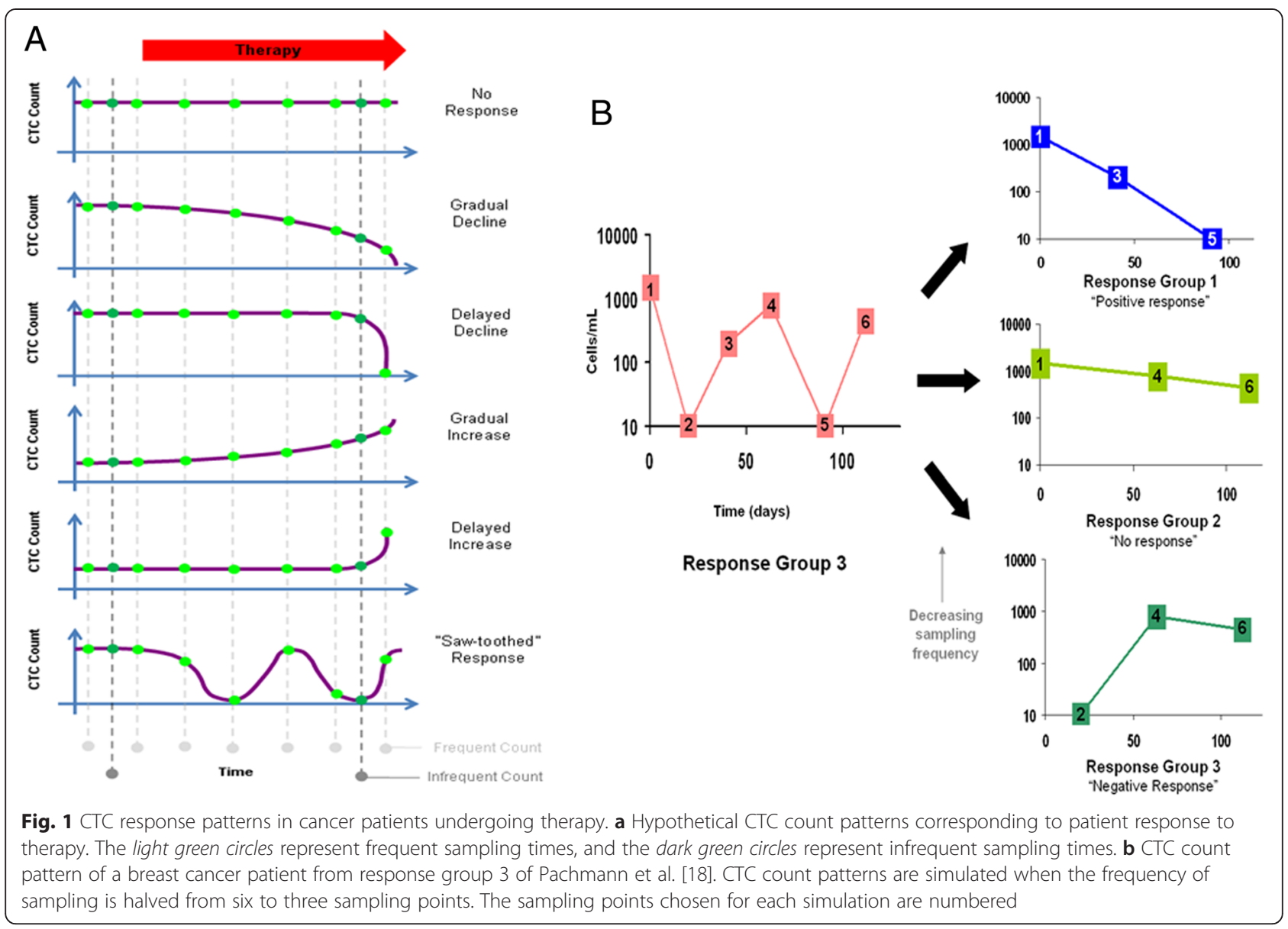

sampling dates chosen, the patient could appear to have no CTCs during disease progression in 2008 (Fig. 2a).

(iii) We monitored our own prostate cancer patient using the CellSearch assay. A spike in CTCs from 1 to 5 was observed within 1 month, which correlated with prostate-specific antigen (PSA) levels and disease progression by PET/CT imaging (Fig. 2b). We simulated the count patterns observed when the frequency of blood sampling is halved, using alternate time points. The two different count patterns produced show that the spike in CTCs could be missed if CTC sampling were less frequent (Fig. 2b).

(iv) Another case is our own patient with metastatic prostate cancer, who had weekly CTC sampling at each chemotherapy session. CTCs were isolated using a previously published size-exclusion method [26]. Using this method, which is not dependent on epithelial markers, mesenchymal CTCs that have been associated with therapeutic resistance and disease progression [21] can be captured together with the epithelial ones. For this patient, transient saw-toothed-like spikes in CTC count, with a duration span of not more than 1 month, were observed, and these transient increases preceded progression of osseous disease as shown by a PET bone scan (Fig. 2c). We performed a simulation test to determine the CTC count pattern generated when the sampling frequency was hypothetically decreased from weekly to monthly. Different start dates and intervals of 4-7 weeks between CTC measurements were simulated. Interestingly, $57.2 \%$ (8 out of 14 ) of the simulated models generated failed to recapitulate the saw-toothed pattern of response group 3. In fact, these simulated count patterns ("Simulation 1", Fig. 2c) resemble more closely the invariable pattern of response group 2 in Pachmann et al.'s study [18].

All four case studies, using different CTC isolation technologies including the FDA-approved CellSearch assay, demonstrate how patients using a sub-optimal count frequency may end up with different count patterns indicative of different therapeutic responses and varied predictions of relapse-free survival. Depending on the start date and sampling points chosen, there is a good chance that the physician may be misled into concluding that the patient is responding to treatment, when the latter may in fact be developing resistance to therapy. Published studies typically measured CTCs at monthly intervals during therapy to assess the patients' 


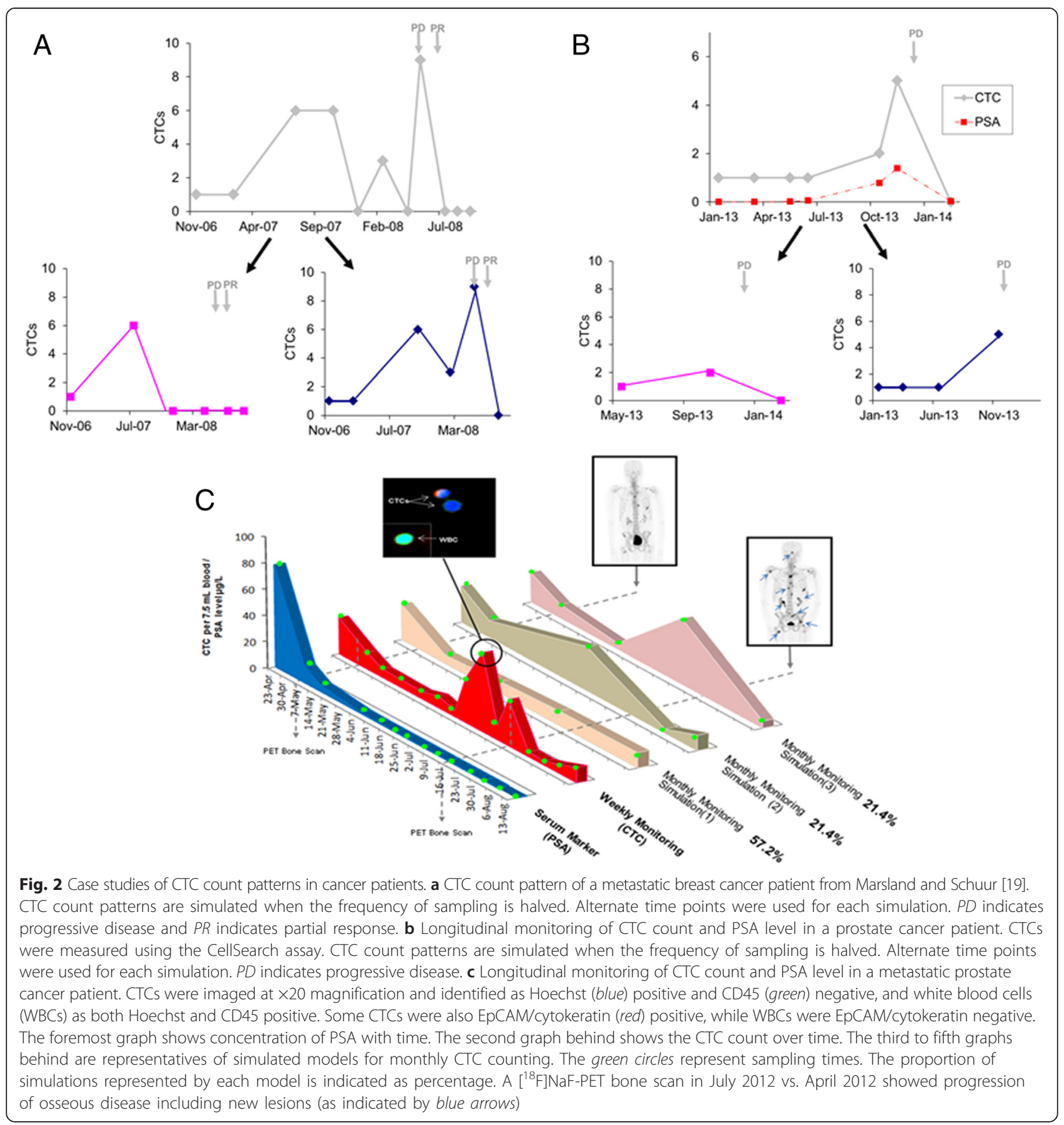

responses [19-21]. However, as there is still a lack of understanding of the kinetics of CTC dissemination and turnover in blood in response to treatment, it is unknown if a monthly frequency offers sufficient analytical resolution in deciphering the patient's therapeutic response pattern based on changes in CTC number.

\section{CTC enumeration is only the tip of the iceberg}

The above case studies demonstrate the possibility of misleading interpretation of disease progression and treatment responses based on CTC numbers, given insufficient sampling. This assumption is made purely based on CTC total numbers. Apart from the choice of sampling frequency, other factors may further confound attempts to decipher the patients' actual therapeutic responses based on CTC number. One such factor is the technology used in isolating CTCs from patients' peripheral blood samples. Currently, the understanding of CTCs is very much dependent on the technological approaches used for their detection and isolation. Many 
different CTC detection technologies have been developed, including nucleic acid-based detection [27, 28], detection based on physical properties such as larger size of epithelial cells [29], differences in density [30], charge [31], migratory properties [32,33], and properties of specific cell types $[34,35]$. Approaches of isolation of CTCs by virtue of their increased size using filtration are limited by the variability in heterogeneous CTC sizes. The most widely used CTC isolation approach relies on antibody-based capture of CTCs which express epithelial cell surface markers such as the epithelial cell adhesion molecule (EpCAM) that are absent from normal leukocytes [4, 32, 33]. The FDA-approved CellSearch system (Veridex) which uses this approach is the most standardized platform but suffers from low sensitivity [36]. This approach is also limited by the failure to detect CTCs that have undergone epithelial-mesenchymal transition (EMT), a key process involved in metastasis [37].

Given the lack of a gold standard to compare CTC isolation technologies to, it remains a question whether current methods are detecting all CTCs reliably [38]. Even though technological advances have improved CTC isolation efficiency, due to the universal issue of leukocyte contamination, identification of all CTCs with heterogeneous expression markers can be challenging. Furthermore, not all CTCs detected may be clinically relevant [38]. Patients with benign inflammatory conditions may have viable circulating epithelial cells detected by current CTC assays [39]. Because some CTCs may be undetected and some detected CTCs may not be clinically relevant, CTC enumeration by itself may not be a good marker for disease progression. An ambiguous choice of sampling time points only serves to further undermine the utility of CTC counting for clinical use. To this end, further characterization of the detected CTCs by size, the presence of clusters [40], or other phenotypic or molecular properties may add information for reliable prediction of treatment responses.

\section{Sampling for molecular characterization}

CTCs may be shed from different sites within the tumor, which are heterogeneous, or from metastases. Molecular characterization of the CTCs such as expression profiling to detect organ-specific metastatic signatures may aid diagnostic and therapeutic strategies [38]. Molecular analysis of CTCs may provide a "real time" noninvasive approach for tumor cell genotyping, which can be repeated during the course of therapy to monitor the acquisition of novel genetic abnormalities in response to drug exposure. Moreover, different CTC parameters can influence how CTCs reflect disease progression. The proportion of cells in proliferative or apoptotic status varies during treatment and across patients [41]. The androgen receptor (AR) subcellular localization varies during treatment of androgen deprivation therapy [42]. A simple enumeration of CTCs without molecular and/or phenotypic characterization may lead to wrongful clinical assumptions and consequences. Like CTC enumeration, appropriate choice of sampling frequency for molecular and/or phenotypic characterization may be necessary for accurate interpretation of the patients' responses to therapies. In view of this, we describe below two hypothetical examples of how insufficient sampling may demonstrate the possibility of misleading interpretation of disease progression and treatment responses based on molecular characterization of CTCs.

Advanced CTC analysis, such as genomic profiling, will likely increase the clinical value of CTCs as biomarkers and therapeutic targets. The use of targeted therapies has achieved considerable success; however, many patients relapse due to drug resistance [43]. The detection of small numbers of resistant CTCs could prompt the clinician to use alternative treatment strategies that might prevent resistant clones from expanding to dominate the tumor cell population [43]. Using serial CTC samples from lung cancer patients, Maheswaran et al. demonstrated evolution of T790M and other epidermal growth factor receptor (EGFR)-activating mutations during treatment with the tyrosine kinase inhibitor, Gefitinib [20]. The T790M missense mutation occurs within the EGFR kinase domain and prevents binding of Gefitinib to this region while preserving catalytic activity [44]. In their study, the sampling interval used varied from 30 to 100 days, which corresponds to 2-7 biweekly cycles of chemotherapy [20]. To save the patient a few cycles of ineffective therapy, we propose increasing the frequency of CTC sampling, which may permit earlier detection of $T 790 M$ emergence. This, in turn, will enable earlier initiation of subsequent chemotherapy to eradicate the resistant clones, which may improve survival outcome $[45,46]$. In a hypothetical situation as depicted in Fig. 3a, the choice of a bi-weekly monitoring interval over a bi-monthly one saves the patient about 6 weeks of ineffective treatment with the targeted therapy, due to earlier detection of the mutation conferring resistance with more frequent sampling. Subsequent therapy can then be initiated earlier, and earlier time to chemotherapy initiation of 4-8 weeks has been shown to confer significant overall survival benefit in patients with colorectal and breast cancers [47-49].

Besides mutation analysis, other molecular assays of CTCs have also been investigated as indicators of treatment response. Using an RNA in situ hybridization assay on CTCs isolated from an index breast cancer patient, $\mathrm{Yu}$ et al. demonstrated association of disease progression and treatment failure with EMT [21]. In this study, CTCs were assayed at 1-3-monthly intervals, with the mesenchymal phenotype correlating positively with CTC 


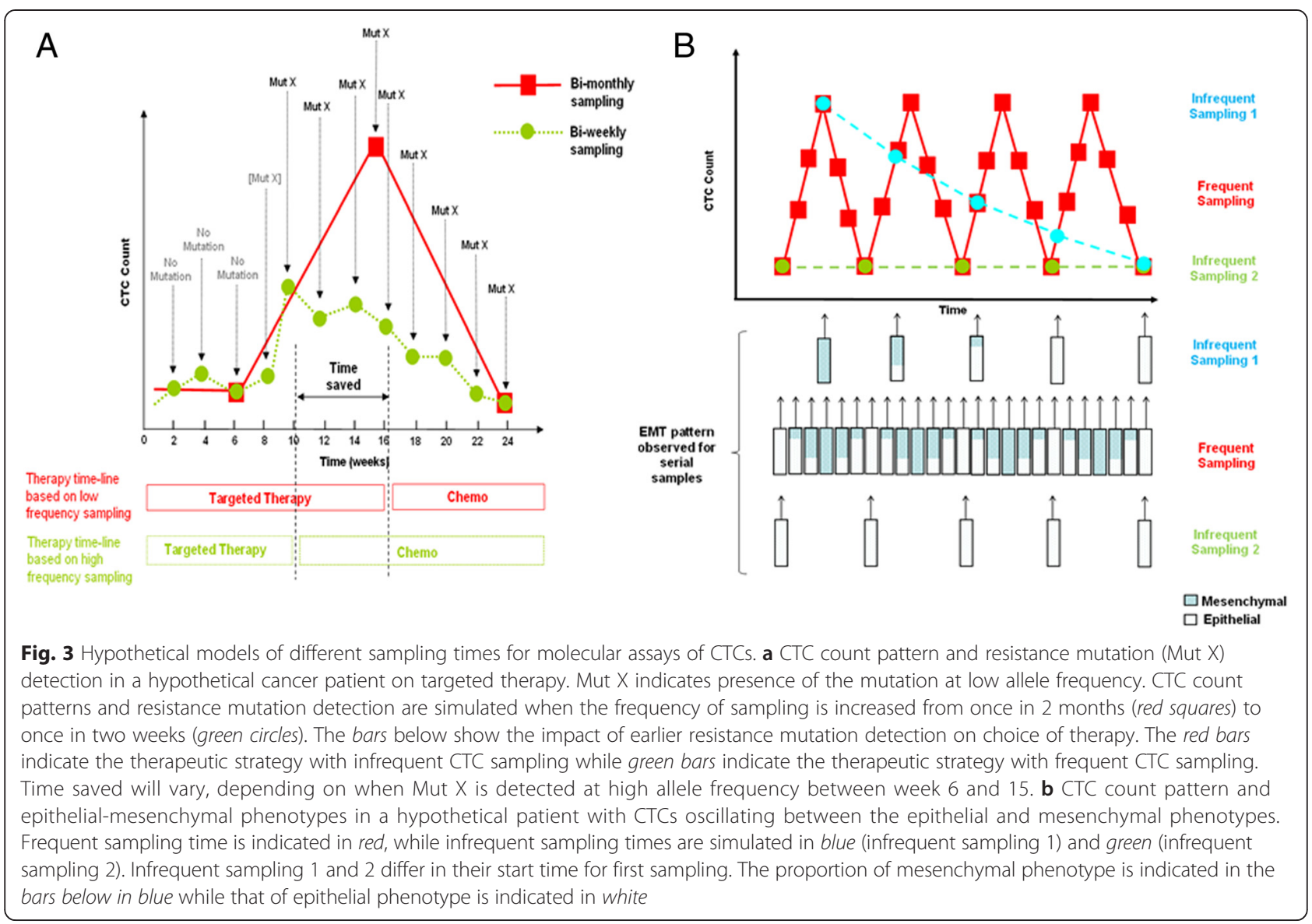

numbers [21]. Similar to CTC count, the dynamics of EMT in relation to metastasis and chemotherapeutic treatment is not well understood. As shown in a hypothetical situation (Fig. 3b), for a patient with CTCs oscillating between epithelial and mesenchymal phenotype with time, inadequate sampling may give rise to a misleading trend, e.g., an apparent mesenchymal-toepithelial phenotypic change of "infrequent sampling 1" can give a false impression of therapeutic responsiveness, while a perpetual epithelial phenotype with low CTC count of "infrequent sampling 2" can mislead physicians into thinking that the disease is under remission.

\section{Perspective}

The case studies presented above highlight the importance of understanding the precise kinetics of CTC dissemination before optimal count frequency can be assigned for large-scale trials and future clinical practice. As shown in the two hypothetical examples above, without appropriate frequency of CTC sampling, molecular analysis of CTCs may lead to potentially wrong assumptions or delayed diagnosis with clinical consequences. To this end, we propose that initial systematic studies involving highly frequent (e.g., weekly) sampling to understand the kinetics of CTC dissemination in patients of different cancer types, stages of disease, and treatments. A high-resolution "count-scape" will permit visualization of the actual CTC response patterns manifested in different scenarios. In the case of patients with saw-toothed responses, measurement of the range of duration spans of the CTC spikes may then lead to better understanding of the kinetics of CTC spurts and enable determination of the optimal sampling intervals to employ. This systematic approach is perceivably superior to the arbitrary manner in which sampling frequencies are currently being selected and will likely lead to a better gauge of the actual therapeutic responses based on changes in CTC count. While the high cost and resource requirements associated with highly frequent CTC sampling may be prohibitive, these may be overcome in the near future by technological advances leading to low-cost and high-throughput CTC isolation devices. Before CTC-based molecular markers can be translated to the real-world clinical setting, systematic studies with high-frequency sampling of CTCs will likely be required to establish the dynamics of the phenotypic and genetic changes occurring in CTCs.

CTCs capture real-time information about the biology of the cancer; changes in CTCs can thus reveal changes 
in disease status. The ultimate goal in clinical application of CTCs is its incorporation into disease management strategies. CTCs may be used, in conjunction with radiologic imaging, serum tumor markers, and clinical assessment, for real-time monitoring of disease status and therapeutic efficacy. At the moment, the sampling frequency represents a major conundrum and an unresolved unknown in the study and clinical application of CTCs. Current studies in CTC are probably limited in sampling frequency more as a result of cost and resource implications than scientific rationale. To fulfill the full clinical potential of CTCs, an initial study involving high-frequency blood sampling appears to be the unavoidable trip that all CTC researchers must take to ensure there is no loss of crucial information during time-course investigations.

\section{Ethics committee approval}

Blood was obtained from patient described in case study (2) with approval from the Institutional Review Board (IRB) of National University of Singapore (NUS), following written informed consent.

\begin{abstract}
Abbreviations
CT: computed tomography; CTC: circulating tumor cell; CETC: circulating epithelial tumor cell; EGFR: epidermal growth factor receptor; EpCAM: epithelial cell adhesion molecule; EMT: epithelial-mesenchymal transition; PR: partial response; PFS: progression-free survival; PD: progressive disease; OS: overall survival; PET: positron emission tomography; PSA: prostate-specific antigen; WBC: white blood cell.
\end{abstract}

\section{Competing interests}

Mo-Huang Li is the CEO of CellSievo Pte. Ltd., Singapore. The other authors declare that they have no competing interests.

\section{Authors' contributions}

$\mathrm{ST}, \mathrm{DT}, \mathrm{DF}, \mathrm{MHL}$, and SO participated in the provision of study materials or patient. SML, HWC, KMLT, and ESCK participated in the acquisition and interpretation of data. All authors were involved in the writing, review, or revision of the manuscript. All authors read and approved the final manuscript.

\section{Acknowledgements}

This work is supported by Exploit Technologies (EPTL) A*STAR Singapore (EPTL/10-S10COT-0019), A*STAR Science and Engineering Research Council Public Service Fund (SERC PSF) (1121202021), National University of Singapore Yong Loo Lin School of Medicine Bridging Grant for Established Researchers (R179-000-048-733), and Singapore Cancer Society Research Grant (NR11SCS134OM). SML is supported by the Singapore BMRC SERC PSF grant.

\footnotetext{
Author details

'Department of Laboratory Medicine, National University Hospital, Level 3 NUH Main Building, 5 Lower Kent Ridge Road, Singapore 119074, Singapore. ${ }^{2}$ Department of Pathology, National University of Singapore, Level 3 NUH Main Building, 5 Lower Kent Ridge Road, Singapore 119074, Singapore. ${ }^{3}$ Tucker Medical, Novena Specialist Center, 8 Sinaran Drive \#04-03, Singapore 307470, Singapore. ${ }^{4}$ Radlink PET and Cardiac Imaging Center, 290 Orchard Road, \#08-06 Paragon Medical, Singapore 238859, Singapore. ${ }^{5}$ CellSievo Private Limited Singapore, Block 289A, Bukit Batok St. 25, \#15-218, Singapore 650289, Singapore.
}

Received: 23 April 2015 Accepted: 15 June 2015

Published online: 25 June 2015

\section{References}

1. Ashworth TR. A case of cancer in which cells similar to those in the tumors were seen in the blood after death. Aus Med J. 1869;14:146-9.

2. Lang JM, Casavant BP, Beebe DJ. Circulating tumor cells: getting more from less. SciTransl Med. 2012;4:141ps13.

3. King JD, Casavant BP, Lang JM. Rapid translation of circulating tumor cell biomarkers into clinical practice: technology development, clinical needs and regulatory requirements. Lab Chip. 2014;14:24-31.

4. Cristofanilli M, Budd GT, Ellis MJ, Stopeck A, Matera J, Miller MC, et al. Circulating tumor cells, disease progression, and survival in metastatic breast cancer. N Engl J Med. 2004;351:781-91.

5. Lucci A, Hall CS, Lodhi AK, Bhattacharyya A, Anderson AE, Xiao L, et al. Circulating tumour cells in non-metastatic breast cancer: a prospective study. Lancet Oncol. 2012;13:688-95.

6. Moreno JG, Miller MC, Gross S, Allard WJ, Gomella LG, Terstappen LW. Circulating tumor cells predict survival in patients with metastatic prostate cancer. Urology. 2005;65:713-8.

7. Cohen SJ, Punt CJ, lannotti N, Saidman BH, Sabbath KD, Gabrail NY, et al. Prognostic significance of circulating tumor cells in patients with metastatic colorectal cancer. Ann Oncol. 2009;20:1223-9.

8. Hofman V, llie MI, Long E, Selva E, Bonnetaud C, Molina T, et al. Detection of circulating tumor cells as a prognostic factor in patients undergoing radical surgery for non-small-cell lung carcinoma: comparison of the efficacy of the Cell Search Assay ${ }^{\top M}$ and the isolation by size of epithelial tumor cell method. Int J Cancer. 2011;29:1651-60.

9. Poveda A, Kaye SB, McCormack R, Wang S, Parekh T, Ricci D, et al. Circulating tumor cells predict progression free survival and overall survival in patients with relapsed/recurrent advanced ovarian cancer. Gynecol Oncol. 2011;122:567-72.

10. Ramirez JM, Fehm T, Orsini M, Cayrefourcq L, Maudelonde T, Pantel K, et al. Prognostic relevance of viable circulating tumor cells detected by EPISPOT in metastatic breast cancer patients. Clin Chem. 2014;60:214-21.

11. Igawa S, Gohda K, Fukui T, Ryuge S, Otani S, Masago A, et al. Circulating tumor cells as a prognostic factor in patients with small cell lung cancer. Oncol Lett. 2014;7:1469-73.

12. Hayes DF, Cristofanilli M, Budd GT, Ellis MJ, Stopeck A, Miller MC, et al. Circulating tumor cells at each follow-up time-point during therapy of metastatic breast cancer patients predict progression-free and overall survival. Clin Cancer Res. 2006;12:4218-24.

13. Nolé F, Munzone E, Zorzino L, Minchella I, Salvatici M, Botteri E, et al. Variation of circulating tumor cell levels during treatment of metastatic breast cancer: prognostic and therapeutic implications. Ann Oncol. 2008;19:891-7.

14. Bidard FC, Peeters DJ, Fehm T, Nolé F, Gisbert-Criado R, Mavroudis D, et al. Clinical validity of circulating tumour cells in patients with metastatic breast cancer: a pooled analysis of individual patient data. Lancet Oncol. 2014;15:406-14.

15. de Bono JS, Scher HI, Montgomery RB, Parker C, Miller MC, Tissing H, et al. Circulating tumor cells predict survival benefit from treatment in metastatic castration-resistant prostate cancer. Clin Cancer Res. 2008;14:6302-9.

16. Cohen SJ, Punt CJ, lannotti N, Saidman BH, Sabbath KD, Gabrail NY, et al. Relationship of circulating tumor cells to tumor response, progression-free survival, and overall survival in patients with metastatic colorectal cancer. J Clin Oncol. 2008;26:3213-21.

17. Harris L, Fritsche $H$, Mennel R, Norton L, Ravdin P, Taube S, et al. American Society of Clinical Oncology 2007 update of recommendations for the use of tumor markers in breast cancer. J Clin Oncol. 2007;25:5287-312.

18. Pachmann K, Camara O, Kavallaris A, Krauspe S, Malarski N, Gajda M, et al. Monitoring the response of circulating epithelial tumor cells to adjuvant chemotherapy in breast cancer allows detection of patients at risk of early relapse. J Clin Oncol. 2008;26:1208-15.

19. Marsland T, Schuur ER. Circulating tumor cell data: integration with imaging and serum tumor markers for metastatic breast cancer patient management. Case Rep Oncol. 2014;7:175-81.

20. Maheswaran S, Sequist LV, Nagrath S, Ulkus L, Brannigan B, Collura CV, et al. Detection of mutations in EGFR in circulating lung-cancer cells. N Engl J Med. 2008;359:355-77.

21. Yu M, Bardia A, Wittner BS, Stott SL, Smas ME, Ting DT, et al. Circulating breast tumor cells exhibit dynamic changes in epithelial and mesenchymal composition. Science. 2013;339:580-4. 
22. Pachmann K, Camara O, Kohlhase A, Rabenstein C, Kroll T, Runnebaum IB, et al. Assessing the efficacy of targeted therapy using circulating epithelial tumor cells (CETC): the example of SERM therapy monitoring as a unique tool to individualize therapy. J Cancer Res Clin Oncol. 2011;137:821-8.

23. Marusyk A, Almendro V, Polyak K. Intra-tumour heterogeneity: a looking glass for cancer? Nat Rev Cancer. 2012;12:323-34.

24. Pierga JY, Bidard FC, Mathiot C, Brain E, Delaloge S, Giachetti S, et al. Circulating tumor cell detection predicts early metastatic relapse after neoadjuvant chemotherapy in large operable and locally advanced breast cancer in a phase II randomized trial. Clin Cancer Res. 2008;14:7004-10.

25. Riethdorf S, Müller V, Zhang L, Rau T, Loibl S, Komor M, et al. Detection and HER2 expression of circulating tumor cells: prospective monitoring in breast cancer patients treated in the neoadjuvant Gepar Quattro trial. Clin Cancer Res. 2010;16:2634-45.

26. Lim LS, Hu M, Huang MC, Cheong WC, Gan AT, Looi XL, et al. Microsieve lab-chip device for rapid enumeration and fluorescence in situ hybridization of circulating tumor cells. Lab Chip. 2012;12:4388-96.

27. Stathopoulou A, Vlachonikolis I, Mavroudis D, Perraki M, Kouroussis CH, Apostolaki S, et al. Molecular detection of cytokeratin-19-positive cells in the peripheral blood of patients with operable breast cancer: evaluation of their prognostic significance. J Clin Oncol. 2002;20:3404-12.

28. Bossolasco P, Ricci C, Farina G, Soligo D, Pedretti D, Scanni A, et al. Detection of micrometastatic cells in breast cancer by RT-PCR for the mammaglobin gene. Cancer Detect Prev. 2002;26:60-3.

29. Vona G, Sabile A, Louha M, Sitruk V, Romana S, Schütze $K$, et al. Isolation by size of epithelial tumor cells: a new method for the immunomorphological and molecular characterization of circulating tumor cells. Am J Pathol. 2000;156:57-63.

30. Gertler R, Rosenberg R, Fuehrer K, Dahm M, Nekarda H, Siewert JR. Detection of circulating tumor cells in blood using an optimized density gradient centrifugation. Recent Results Cancer Res. 2003;162:149-55.

31. Becker FF, Wang XB, Huang Y, Pethig R, Vykoukal J, Gascoyne PR. Separation of human breast cancer cells from blood by differential dielectric affinity. Proc Natl Acad Sci U S A. 1995;92:860-4.

32. Nagrath S, Sequist LV, Maheswaran S, Bell DW, Irimia D, Ulkus L, et al. Isolation of rare circulating tumour cells in cancer patients by microchip technology. Nature. 2007:450:1235-9.

33. Stott SL, Hsu CH, Tsukrov DI, Yu M, Miyamoto DT, Waltman BA, et al. Isolation of circulating tumor cells using a microvortex-generating herringbone-chip. Proc Natl Acad Sci U S A. 2010;107:18392-7.

34. Alix-Panabières C. EPISPOT assay: detection of viable DTCs/CTCs in solid tumor patients. Recent Results Cancer Res. 2012;195:69-76.

35. Kojima T, Hashimoto Y, Watanabe $Y$, Kagawa S, Uno F, Kuroda S, et al. A simple biological imaging system for detecting viable human circulating tumor cells. J Clin Invest. 2009;119:3172-81.

36. Ross JS, Slodkowska EA. Circulating and disseminated tumor cells in the management of breast cancer. Am J Clin Pathol. 2009;132:237-45.

37. Grover PK, Cummins AG, Price TJ, Roberts-Thomson IC, Hardingham JE. Circulating tumour cells: the evolving concept and the inadequacy of their enrichment by EpCAM-based methodology for basic and clinical cancer research. Ann Oncol. 2014;25:1506-16.

38. Plaks V, Koopman CD, Werb Z. Circulating tumor cells. Science. 2013;341:1186-8.

39. Pantel K, Denève E, Nocca D, Coffy A, Vendrell JP, Maudelonde T, et al. Circulating epithelial cells in patients with benign colon diseases. Clin Chem. 2012;58:936-40.

40. Aceto N, Bardia A, Miyamoto DT, Donaldson MC, Wittner BS, Spencer JA, et al. Circulating tumor cell clusters are oligoclonal precursors of breast cancer metastasis. Cell. 2014;158:1110-22.

41. Stott SL, Lee RJ, Nagrath S, Yu M, Miyamoto DT, Ulkus L, et al. Isolation and characterization of circulating tumor cells from patients with localized and metastatic prostate cancer. Sci Transl Med. 2010;2:25ra23.

42. Dago AE, Stepansky A, Carlsson A, Luttgen M, Kendall J, Baslan T, et al. Rapid phenotypic and genomic change in response to therapeutic pressure in prostate cancer inferred by high content analysis of single circulating tumor cells. PLoS One. 2014;9, e101777.

43. McDermott U, Downing JR, Stratton MR. Genomics and the continuum of cancer care. N Engl J Med. 2011;364:340-50.

44. Kobayashi S, Boggon TJ, Dayaram T, Jänne PA, Kocher O, Meyerson M, et al. EGFR mutation and resistance of non-small-cell lung cancer to gefitinib. N Engl J Med. 2005;352:786-92.
45. Kuo CH, Lin SM, Lee KY, Chung FT, Hsieh MH, Fang YF, et al. Subsequent chemotherapy improves survival outcome in advanced non-small-cell lung cancer with acquired tyrosine kinase inhibitor resistance. Clin Lung Cancer. 2010;11:51-6.

46. Guo R, Chen X, Wang T, Zhang Z, Sun J, Shu Y. Subsequent chemotherapy reverses acquired tyrosine kinase inhibitor resistance and restores response to tyrosine kinase inhibitor in advanced non-small-cell lung cancer. BMC Cancer. 2011;11:20-90.

47. Biagi JJ, Raphael MJ, Mackillop WJ, Kong W, King WD, Booth CM. Association between time to initiation of adjuvant chemotherapy and survival in colorectal cancer: a systematic review and meta-analysis. JAMA. 2011;305:2335-42.

48. Berglund A, Cedermark B, Glimelius B. Is it deleterious to delay the start of adjuvant chemotherapy in colon cancer stage III? Ann Oncol. 2008;19:400-2.

49. Yu KD, Huang S, Zhang JX, Liu GY, Shao ZM. Association between delayed initiation of adjuvant CMF or anthracycline-based chemotherapy and survival in breast cancer: a systematic review and meta-analysis. BMC Cancer. 2013;13:240

\section{Submit your next manuscript to BioMed Central and take full advantage of:}

- Convenient online submission

- Thorough peer review

- No space constraints or color figure charges

- Immediate publication on acceptance

- Inclusion in PubMed, CAS, Scopus and Google Scholar

- Research which is freely available for redistribution 